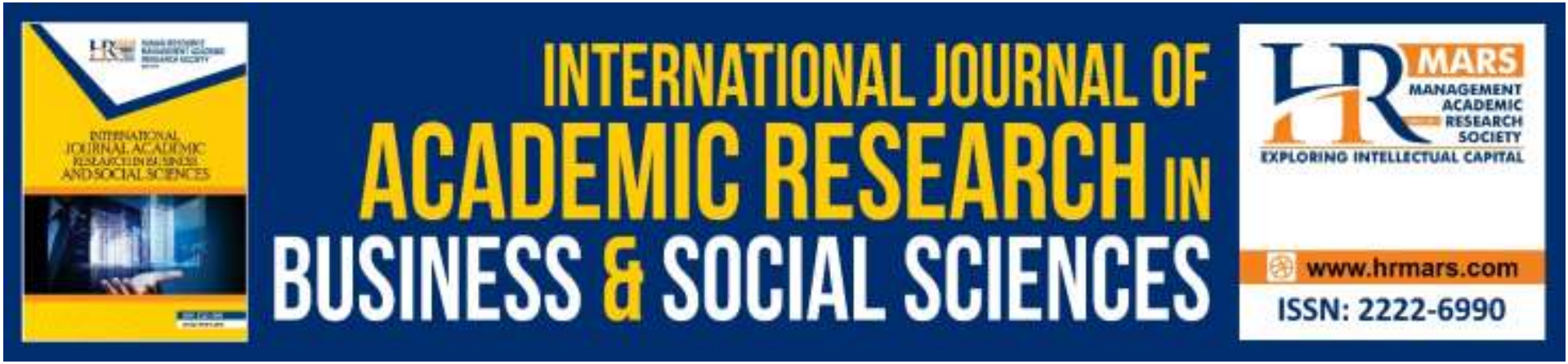

\title{
Differences in Cultural Perspectives on Cyberbullying-Related Words
}

Kev Yi Beng, Tan Kim Hua

To Link this Article: http://dx.doi.org/10.6007/IJARBSS/v9-i10/6444

DOI: 10.6007/IJARBSS/v9-i10/6444

Received: 15 August 2019, Revised: 10 September 2019, Accepted: 30 September 2019

Published Online: 24 Oct 2019

In-Text Citation: (Beng, Hua, 2019)

To Cite this Article: Beng, K. Y., Hua, T. K. (2019) Differences in Cultural Perspectives on Cyberbullying-Related Words. International Journal of Academic Research in Business and Social Sciences, 9(10). 22-36

Copyright: @ 2019 The Author(s)

Published by Human Resource Management Academic Research Society (www.hrmars.com)

This article is published under the Creative Commons Attribution (CC BY 4.0) license. Anyone may reproduce, distribute, translate and create derivative works of this article (for both commercial and non-commercial purposes), subject to full attribution to the original publication and authors. The full terms of this license may be seen at: http://creativecommons.org/licences/by/4.0/legalcode

Vol. 9, No. 10, 2019, Pg. 22 - 36

http://hrmars.com/index.php/pages/detail/IJARBSS

JOURNAL HOMEPAGE

Full Terms \& Conditions of access and use can be found at http://hrmars.com/index.php/pages/detail/publication-ethics 


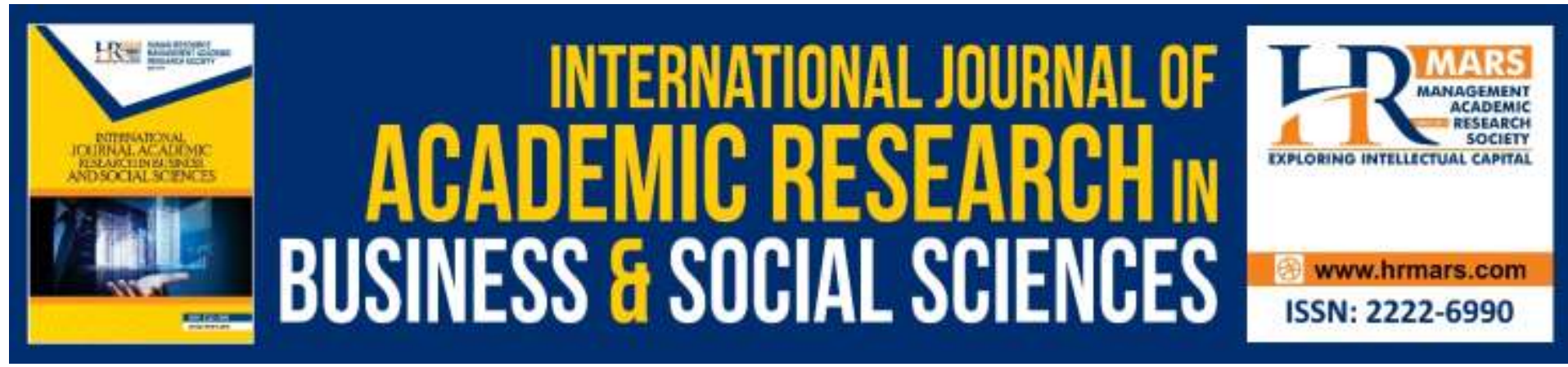

\title{
Differences in Cultural Perspectives on Cyberbullying-Related Words
}

\author{
Kev Yi Beng, Dr Tan Kim Hua \\ Universiti Kebangsaan Malaysia, Malaysia
}

\begin{abstract}
Cyberbullying is on the rise worldwide. In Malaysia, several adolescents committed suicide due to victimisation of cyberbullying. Research is thus necessary to gain an in-depth understanding of the reasons for cyberbullying and then provide a solution to the problem. This study addresses cyberbullying using a survey questionnaire that determines the words that the public considers to be demeaning. The survey questionnaire is conducted through Google Form and is completed by 44 respondents. Three categories of cyberbullying are identified, namely, appearance, intelligence, and worthiness. Once the demeaning words per category are identified, the highest-rated words are gathered and presented to participants from different cultural backgrounds. An interview is conducted to investigate the understanding of those words. Although respondents from different cultural backgrounds have mixed interpretations of the presented words, results found that avoiding using the identified demeaning words is an effective solution to cure cyberbullying. Pedagogical implications are also suggested on the basis of findings. Eliminating cyberbullying is the responsibility of all members of the nation.
\end{abstract}

Keywords: Cyberbullying, Words, Phrases, Pedagogical Implication, Malaysia

\section{Introduction}

With the advancement of technology and the Internet, access to social media is literally at people's fingertips. People can post status on Facebook, share a personal photo on Twitter and comment on others' status on social media with ease. However, as access to social media becomes increasingly easy, so does the occurrence of cyberbullying. On the Internet, people can create a dummy account to comment anonymously without fear of the consequences of their actions. Moreover, people can comment anything they wish on social media.

Such irresponsible behaviours of social media users generate cyberbullying. Victims of cyberbullying suffer from humiliation and depression, and those who are constantly cyberbullied on social media isolate themselves from society. In extreme cases, cyberbullied victims commit suicide. 


\section{Issues}

Students who experience bullying or cyberbullying are nearly two times more likely to attempt suicide (Hinduja \& Patchin, 2018). Findings indicated that being a victim of cyberbullying, but not a perpetrator, was associated with an increased risk of suicide (Kim, Walsh, Pike \& Thompson, 2019). In Malaysia, a study conducted by the Malaysian Psychiatric Association found that suicide rates have increased alarmingly by $60 \%$ since the $1960 \mathrm{~s}$ (Dudley, 2018). Pillay (2017) reported that the number of people crying out for help due to suicidal thoughts have increased by $16 \%$ from 21,256 in 2015 to 24,821 in 2016. Befrienders Kuala Lumpur publicity director, Ardy Ayadali, stated that the number of people who called them due to suicidal intentions has increased to 7,446 in 2016 from 5,739 in 2015 (Pillay, 2017). These figures show the increment of people having suicidal intentions. Befrienders Kuala Lumpur is a non-profit organisation that provide emotional support 24 hours a day to people who are lonely, in distress, in despair and are having suicidal thoughts (Befrienders, 2019). In addition, the World Health Organization (WHO) statistics show that suicide is one of the top causes of death worldwide among youth aged 15-29 years old (Dudley, 2018). Recent research has concluded that suicide ideation and attempts among adolescents have nearly doubled since 2008 (Plemmons et al., 2018). At least one in 20 adolescents are involved in suicide incidents in a single year (Andriessen, 2018). Therefore, the rising cyberbullying needs to be solved immediately.

\section{Research Question}

1. What are the words used for cyberbullying?

\section{Research Objective}

1. To identify words that the public perceives to be demeaning and constitute cyberbullying

\section{Literature Review Cyberbullying}

The term 'bullying' has been generally perceived as intentional aggressive behaviours, mobbing, harassment, pestering, silent treatment and ignoring with the outcome of causing pain or discomfort to others (Margeviciute, 2017). Bullying combined with elements of technology is known as cyberbullying (Umesh et al., 2018). Cyberbullying is defined as an intentional, wilful and repeated harm committed through the use of cell phones, computer, electronic or social media devices (Patchin \& Hinduja, 2016). Cyberbullying includes many of the same issues as traditional bullying but extends the aggression beyond the physical schoolyard (Diamanduros \& Downs, 2019). According to Berne, Frisen and Berne (2019), cyberbullying is conducted through modern information and communication technology and can involve for instance hurtful photos, videos and texts that are uploaded to pages on the Internet and offensive text messages. In general, cyberbullying is the act of causing pain to others via the usage of technology such as social media.

Different from traditional bullying, cyberbullying allows offenders to create an anonymous identity by hiding behind technology and faking a social media account to attack victims. Offenders do not need to physically attack their victims and conduct bullying through social media. The distancing effect of technological devices often leads today's youth to say and do cruel things compared with the traditional face-to-face bullying (Donegan, 2012). 
Traditional bullying is limited because the youth typically do not have much energy compared with adults. However, cyberbullying causes emotional harm, which is highly difficult to measure.

\section{Perspectives of Teachers and Students on Cyberbullying}

Umesh et al. (2018) reported that $96 \%$ of teachers who participated in their research claimed no involvement in any fight against cyberbullying. This finding is an adverse situation because students spend half of their day learning in school and teachers are the next people closest to students other than parents. Teachers play an important role in students' lives and thus such statistics are worrisome.

In addition, $47 \%$ of teachers claimed they never heard of cyberbullying cases from their students (Umesh et al., 2018). Such statistical data was possibly caused by the lack of awareness on cyberbullying amongst the teachers. Students are unwilling to inform their teachers that they are being cyberbullied, possibly due to their distrust towards teachers. In addition, students may doubt their teachers' abilities to help them resolve cyberbullying.

Furthermore, Umesh et al. (2018) reported that $87 \%$ of their student-participants claimed that their household does not enforce any form of parental control. This grants students the freedom to roam wherever they prefer in cyberspace. This freedom ultimately ends with a negative outcome. For example, in popular video games such as 'Dota' and 'League of Legends', students who play the games would often release their anger towards their fellow gamers due to extreme frustration or annoyance from losing a match. These threatening and flaming behaviours and actions are considered cyberbullying to adolescents. Thus, although adequate freedom for students is beneficial, parents still need to exert control over their children who have not yet matured in terms of mentality.

\section{Factors that Contribute to Cyberbullying Behaviours}

In a research on Cyber Victimization, Simon (2017) concluded that cyberbullying among adolescents emerges most commonly from relationship problems, such as jealousy, ganging up, physical appearances, family issues and tolerance. Furthermore, the reactive behaviours from school, administrators and students on incidents of cyberbullying are generally uncooperative, passive, inappropriate and ineffective. Such inadequate reactions and poor relationship problems among adolescents are the common rationalizations for cyberbullying and its unresolved incidents.

Additionally, Rashid, Mohamed and Azman (2017) indicated that subjective norm is the essential predictor for adolescents' intention to participate in cyberbullying behaviours. Subjective norm is a social cause that refers to perceived social pressure whether or not to conduct the questioned behaviour (Rashid, Mohamed \& Azman, 2017). Subjective norm is the view considered important by a person who tells another to do or not do certain behaviours, even those that are considered important (Wedayanti \& Giantari, 2016). In other words, subjective norm is the belief of one particular person who assumes that how and what he or she thinks about people is considered vital and motivates others to follow the thought. Specifically, if cyberbullying becomes the norm of society, its practice becomes perfectly normal and everyone can become bullies without bearing the consequences. An adolescent with a subjective norm who believes that it is right to cyberbully others on cyberspace becomes the leading reason for the occurrence of cyberbullying. The bullies, of course, would not feel guilty about their behaviours. Only the victims suffer in the end. For that reason, 
parents and teachers must rectify the subjective norm of children in school and at home. In addition, parents and teachers should not blindly follow the so-called subjective norm of society and need to educate children to think before acting and to always consider the repercussions of their behaviours. Hypothetically, if a society accepts cyberbullying behaviours, then the parents and teachers have the responsibilities to amend and correct such beliefs among children before the results become unbearable. Parents and teachers have the accountability to guide children to a virtuous and righteous path in life.

Nevertheless, a few personality traits can be associated with cyberbullying, namely loneliness, empathy and self-esteem (Ghazali et al., 2016). These personality traits are factors that manifest cyberbullying behaviours in a person.

First, loneliness is perceived as a social isolation and not a physical separation to society. This might isolation a person to commit cyberbullying (Cacioppo \& Hawkley, 2003). A person who is lonely and is rejected by his or her peers would most probably seek and rely on social supports to perpetrate cyberbullying to release their aggression against those who supposedly rejected them beforehand. This person may feel that others bullied them before, and by being anonymous, could easily commit cyberbullying without fear and consideration of the consequences. Second, empathy is a skill learned or an attitude of life that can be used to try to contact someone or to communicate and understand others' experiences or feelings (Halpern, 2003). However, according to Ghazali et al. (2016), low empathy could make people feel safer. If such a person is more comfortable with an anonymous identity online than being known in the real world, the anonymity could cause him or her to cut sensitivity towards others. This scenario ultimately increases his or her inclination to bully in the virtual world. To put it differently, a person with high empathy would put themselves in others' position and would not harm or damage others because they hope that no one would harm them in return, whereas an individual with low empathy would most likely perpetrate cyberbullying when presented with the opportunity to do so.

Last but not least is self-esteem. Ghazali et al. (2016) defined self-esteem as an internal representation of social acceptance and rejection, and a psychological gauge at monitoring the degree whether a person feels included or excluded by his or her peers. An individual with low self-esteem is commonly associated with feelings of unworthiness, incapability and incompetence. Due to such poor feelings, low self-esteem could be continuous and long lasting. An individual with low self-esteem is usually considered to be a cyber victim rather than a cyberbully. Their low confidence possibly makes them easy victims on cyberspace or simply makes them feel victimised on social media because of their feelings of unworthiness.

\section{Pedagogical Implications of Past Research}

Umesh et al. (2018) stated that enforcing robust rules, enacting firm support groups and creating awareness projects may aid in reducing cyberbullying among students. The main characters in cyberbullying, students or adolescents, satisfy the introduction of rules of support groups to tackle developments of cyberbullying. Lai et al. (2017) identified that cyber victims seldom sought help from professional agencies because they are generally more comfortable in sharing their problems with friends and classmates. Therefore, apart from creating and providing professional support agencies for cyber victims, the cause of the problem and the comfort of cyber victims must be considered in determining a solution 
to cyberbullying. Government agencies need to start educating the youth, children and students on the prevention and solution of cyberbullying. Moreover, these young groups should learn how to deal with cyberbullying when their friends inform them of such instances and thereby provide necessary and suitable approaches to solve these problems.

Furthermore, parents ought to educate themselves about cyberbullying issues and start its indispensable prevention by educating their children at home (Simon, 2017). Simon (2017) also believed that the Ministry of Education could train more teachers to counsel students with problems and enhance effective communication skills among teachers and parents. Only when parents and teachers work together can cyberbullying be solved. In fact, the current education system is in desperate need of more teachers who can help students cope with their emotional problems, matters related to mental health, or bullying issues. Moreover, Simon (2017) emphasized that schools should tighten the rules and circulars related to school discipline, such as students with disciplinary issues should undergo counselling sessions with qualified teachers or professionals to help them resolve their issues and not merely give them verbal warning or dismissal.

Yusuf, Hassan and Ibrahim (2018) suggested that children should be pedagogically instructed about online risks and necessary safety. The study suggested that the Ministry of Education could introduce a subject on cyber safety and threats in elementary and high school. Moreover, the Malaysian Communication and Multimedia Commission (MCMC) should periodically organize seminars on online safety and threats to enlighten parents, adolescents and young adults about the dangers in cyberspace, and teach ways to avoid or manage involvement in cyberbullying.

Lazuras, Pyzalski, Barkoukis and Tsorbatzoudis (2012) suggested three implications for education intervention and pedagogical practice in responding to occurrences of cyberbullying. These implications are necessary for positive interventions on new social media use. In addition, such interventions should focus on empathy and moral reasoning training, the roles of educators and parental involvement. Lazuras et al. (2012) pointed out that Information and Communications Technology (ICT) and social media are initiated as early as the pre-adolescent stage. This means that since the youth of today are no strangers to ICT and social media in this era of digital revolution, the proper use of technology is essential to present adverse results and misuse of social media among the new generation. However, attempts to educate young adolescents on the illegal uses of social media are proven to be ineffective because they likely know more about such technology than the adults. As such, friendly pedagogical practice should be developed in the framework of new social media expansion.

The present study aims to enable the users of social media to understand the influences of flawed uses of ICT. Flawed uses include cyberbullying and other similar forms of deviant behaviours. Lazuras et al. (2012) emphasised that the promotion of proper use of technology, and how it could help people lead a better life, should be based on a positive education approach.

Furthermore, on focusing on empathy and moral reasoning training among adolescents, Lazuras et al. (2012) argued that positive caregiver-child relationships and positive role modelling by teachers can curb the prevalence of cyberbullying incidents. This suggestion supports the findings of Ghazali et al. (2016) that low empathy in individuals contribute to committing troublesome cyberbullying behaviours on social media. Lazuras et al. (2012) further explained that cyberbullying perpetrators stated they conducted 
such actions for 'fun' and that they merely considered cyberbullying as another form of webbased entertainment. This is an alarming belief among adolescents who conducted cyberbullying behaviours and display their low to no empathy for cyber victims. Hence, educating young adolescents about the actual effects of cyberbullying behaviours is urgently needed in hopes to minimize the use of unsanitary language in social media.

Lastly, the implications suggested the role of educator and parental involvement. Lazuras et al. (2012) suggested that educators should feel empowered and be specially trained in new social media and should be able to find and cope with cyberbullying incidents. A recent study of teacher trainees in Canada showed that majority of respondents, over $2 / 3$, were aware that cyberbullying was a problem in school. However, only $33 \%$ of the teacher trainees felt confident in accurately finding cyberbullying and only the $15 \%$ were confident in managing and coping with such incidents (Lazuras et al., 2012). These figures show the lack of ability of teachers to find cyberbullying cases and their insufficient knowledge on handling such matters. In addition, at home, parents need to know how to identify the aggressive behaviours of adolescents and be aware of the measures in dealing with issues. Therefore, fostering positive and close relationships between teachers and parents can increase the level of parental control on Internet usage at home. This approach must be accompanied by the increased knowledge of teachers and parents on the technical aspects of defending against cyberbullying. As such, the occurrence of cyberbullying among adolescents would considerably decline.

\section{Language}

People use language to communicate thoughts, cultural beliefs and practices in communities (Amberg \& Vause, 2010). Using language most definitely entails using words. On the one hand, people generally consider words as something in their heads. In fact, psychologists typically have not distinguished 'word' from 'concept' (Bechtel \& Graham, 2014). One particular meaning of a word could be interpreted or understood differently depending on the concept and belief of a person. For instance, the word 'bachelor' can mean a person's concept of bachelorhood (Bechtel \& Graham 2014) yet refer to a 'man who has never been married' in the Oxford dictionary (Oxford, 2019). These mixed interpretations can lead to the conclusion that one particular belief by a person may be interpreted differently depending on the understanding of that person. 


\section{Methodology}

Conceptual Framework

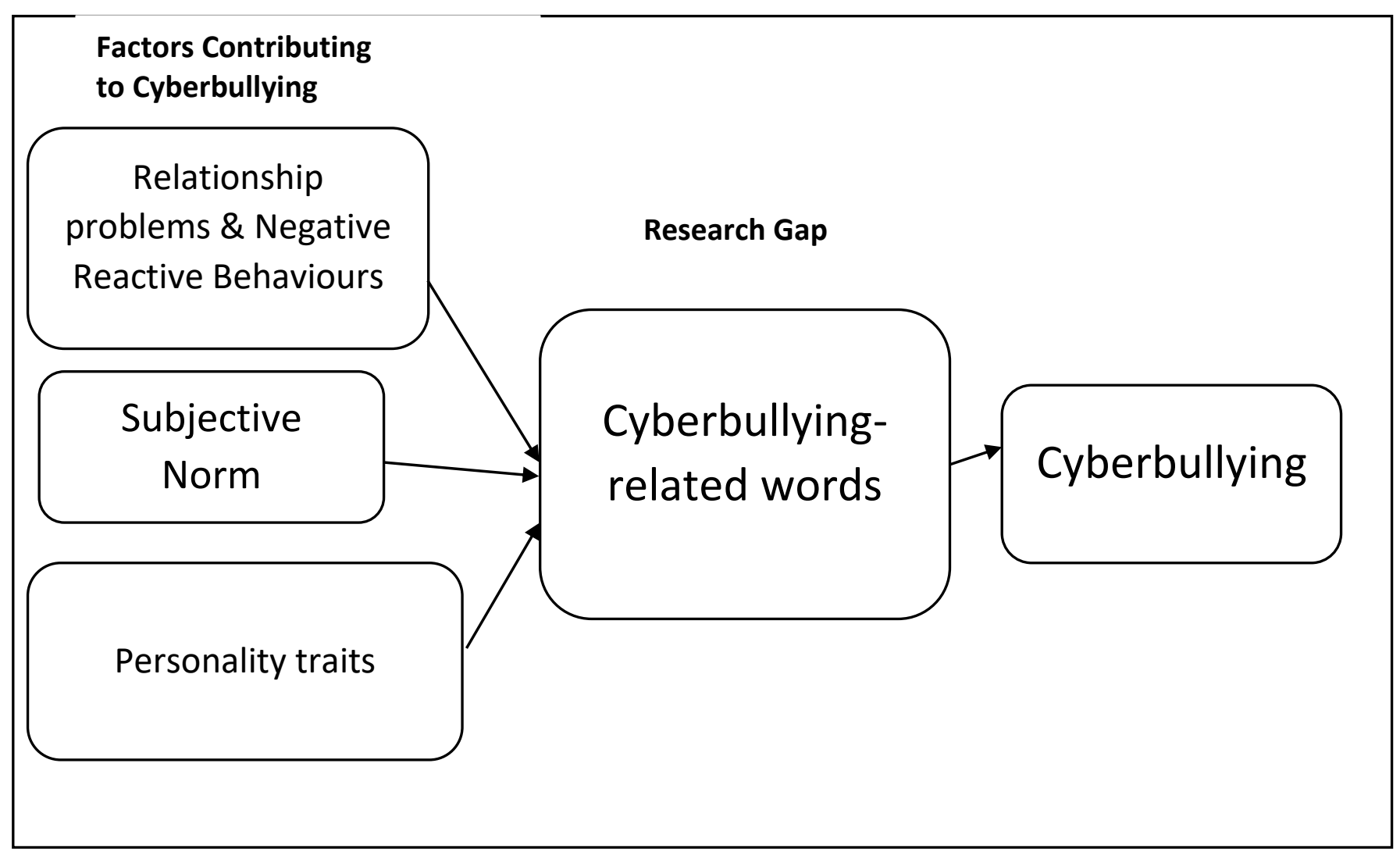

Studying previous relevant literature revealed the factors that contribute to cyberbullying. The identified factors include relationship problems and negative reactive behaviours such as jealousy, physical appearance of victims and bullies, family issues of bullies, tolerance level of bullies. Subjective norm of society and the personality traits of loneliness, low empathy and low self-esteem are also contributing factors. However, there is limited past research on the mortifying-related words used in cyberbullying. These words constitute the research gap of past research. Therefore, the present study aims to determine the words that the public perceived as cyberbullying-related words and the pedagogical implications based on the findings of this research is discussed in the concluding remarks. 


\section{Research Design}

In this study, the sequential explanatory research design is chosen.

Figure 1: Sequential explanatory research design

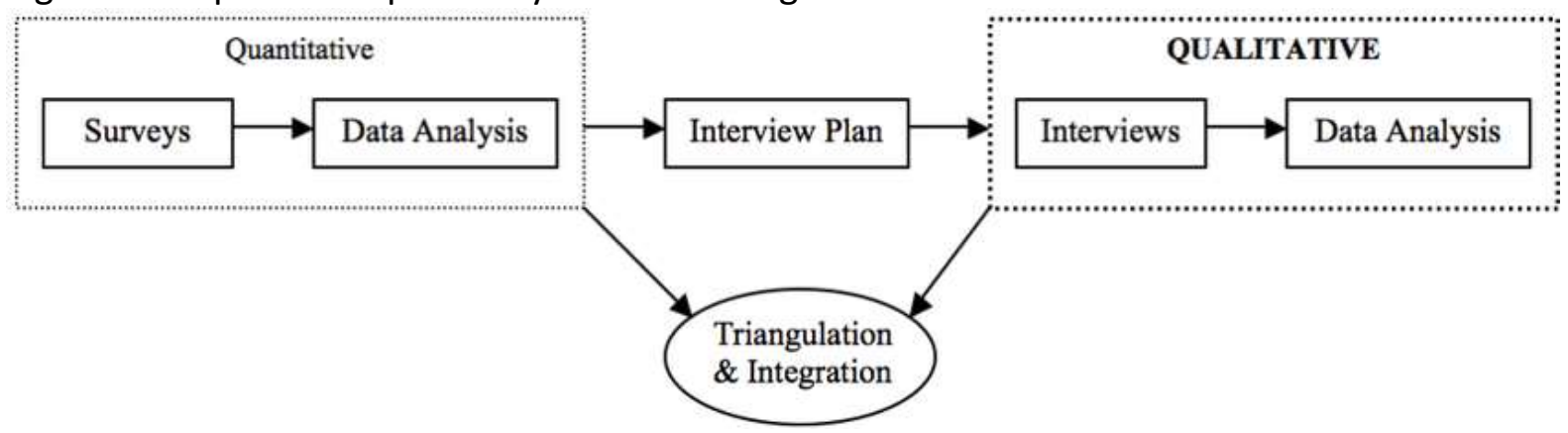

Quantitative research was first carried out followed by qualitative research to leverage both types of data and generate deeper and more reliable findings than those from one data source.

First, quantitative research is conducted using a public online survey to determine the words that the public presumes to be part of cyberbullying or cyber-harassment. After completing the survey data collection, the data collected are analysed and compared to identify the highest-rated words by the public. Following that, an interview was conducted with different ethnic groups to gather their perspectives on the identified words. At this stage, qualitative research is carried out.

\section{Participants}

This study included 44 participants in the quantitative research stage. All participants aged 18-30 years old. With the focus on identifying cyberbullying words in English, all participants had at least a moderate level of English language mastery.

During the qualitative research stage, only a few participants from the previous quantitative research were selected for the interview session on the basis of different ethnic backgrounds. This stage aims to determine if participants with different ethnic backgrounds would have varying understandings and interpretations of the identified cyberbullying words.

\section{Instrument}

In this study, an online survey was created using Google Form. The survey consisted of two parts. The first part collected the basic information of participants, including their email address for the purpose of re-contact in case of their selection for the interview session in the second stage.

The second part of the survey has three open-ended questions for participants to fill in with cyberbullying words that they believe fit the different categories, namely, appearance, intelligence and worthiness.

\section{Results}

Results of participant answers for the three categories related to cyberbullying messages are discussed as follows. 


\section{Appearance}

In the appearance category, 13 out of 44 (29\%) participants included the word 'ugly' in their replies to the survey questionnaire. Other participants answered a similar word to 'ugly' such as 'hideous', 'hodoh', the Mandarin word for 'ugly' that is ' $\mathbb{Z}$ ' and 'Dia ingat dia cantik sangat'.

The second highest-rated word that bears cyberbullying messages in terms of appearance is 'fat'. A total of 11 participants (25\%) included this word, representing the second-highest answer among all the data collected.

The rest of the answers provided by the survey respondents included 'too skinny', 'ordinary', 'plastic', 'you're ugly, 'looking at you will make me get cancer' and 'disgusting'.

\section{Intelligence}

For intelligence, 12 participants (27.27\%) included 'stupid', which is the highest-rated answer given for this category. Four participants (9.09\%) provided the word 'dumb' in their response to the questionnaire on cyberbullying messages regarding intelligence.

The other words provided by participants are 'so clever of you', 'bodoh', 'brainless', 'Do you even go to school', 'dumbass', 'foolish', 'idiot', 'incapable', 'Is your brain a decoration?', 'Looks like special education kid', 'slow', 'ignorance', 'cannot do anything', 'You are brainless and useless', 'You don't deserve to live' and 'noob'.

\section{Worthiness}

In the worthiness category, the highest-rated word is 'useless' from nine participants (20.45\%). According to the data collected, four words tied for second place (4.54\%), including 'poor', 'not valuable', 'cheap' and 'I don't need you'.

The other words given by the participants did not occur twice. These are 'who do you think you are', 'derp', 'doesn't have any value', 'nobody loves you, not even your family', 'rubbish', 'selfish', 'slow', 'I don't need you', 'tak guna', 'useless', 'worthless', 'you are just a kid, your opinions are not relevant', 'you worth nothing', 'you're sampah', 'piece of shit' and 'go die'.

\section{Findings and Discussion}

From the data collected through the survey questionnaire, most of the words gathered contain degrading messages for the targeted audiences. For example, in describing appearance, the most frequently given word is 'ugly'. According to the Cambridge Dictionary, 'ugly' is defined as unpleasant to look at or not attractive. If someone is lacking in attractiveness, the softer way to describe appearance is 'your look is not that up to standard', 'maybe you need some more work done' or 'you could be better'. Using a softer way to remind a person that his or her appearance is not that good will not cause too many negative effects on the person. However, a safer way to avoid causing any cyberbullying case would be to just keep quiet and do not judge or comment about anyone's appearance, intelligence and worthiness.

The word 'ugly' used directly to describe a person's appearance would likely have a strong mortifying message on the person, definitely lower his or her self-esteem, and indirectly leave a scar in that person's life. If circumstances worsen, the person would believe that he or she is an ugly person and is not worthy of anything beautiful. In addition, if the 
word 'ugly' continues to be used, the word gradually brings catastrophic influences on that person's life.

Apart from 'ugly' for appearance, the most frequent words gathered for the other categories are 'stupid' for intelligence and 'useless' for worthiness. With these three words as a basis, an interview was conducted to collect interpretations from people with different cultures, namely, Malay, Chinese and Indian.

For the word 'ugly', all the three participants of Malay, Chinese and Indian cultural backgrounds interpreted the word as not physically attractive and having an unpleasant appearance. All three participants have a different understanding of the word yet all the interpretations bear a similar meaning regarding appearance.

By comparison, the word 'stupid' had mixed interpretations. A Malay respondent defined 'stupid' as incapable of doing something. A Chinese respondent interpreted the word as a person with low Intelligence Quotient, someone who does something with low intelligence or common sense and cannot even solve a simple question. Finally, to the Chinese, someone 'stupid' takes action that does not make sense or causes problems for others. The Indian respondent explained that 'stupid' is having no value in thought. Although this word is under the class of intelligence, both the Malay and Chinese respondents defined 'stupid' in terms of intelligence level and behaviour. For instance, they suggested 'stupid' as the incapacity to do something and inability to solve a simple question. Such interpretations are not incorrect, because according to the Cambridge Dictionary, 'stupid' is defined as 'silly or unwise and showing poor judgment or little intelligence'. Therefore, 'stupid' indeed can be use to describe the actions and intelligence level of a person. Conversely, the Indian respondent claimed the word 'stupid' has no value in thought. This response suggested that, for the Indian respondent, a person's thought that does not bear any value to her is described as 'stupid'. In this category of intelligence, although all three respondents have a diverse understanding of the single word 'stupid', they are all correct nonetheless. The reasonable cause to the varying understanding of the word would be their different cultural experiences growing up.

Finally, the word 'useless' was understood by the Malay respondent as unworthy, the Chinese as incapable to do something or having no contribution and the Indian as having no function or benefit to something. In this part, all three respondents described 'useless' as a word regarding the worthiness of a person. Thus, 'useless' could mean that the said person is not worthy, not contributing anything and has no function or benefit to something. According to the Cambridge Dictionary, 'useless' is defined as 'someone who is not of use, is not working or is not achieving what is needed'. In addition, 'useless' could also mean as not at all doing something. Coincidently, despite their different cultural backgrounds, all three respondents have the same explanation to the word 'useless' in describing a person.

Despite the fact that different people of different cultural backgrounds have varying understanding of cyberbullying words, all these words still carry the same demeaning definition. Therefore, avoiding usage of these cyberbullying words for anyone could prevent any unwanted circumstances.

In addition to demeaning words, several phrases carry similar influences of cyberbullying to audiences. These phrases are, 'Do you even go to school' and 'Please look at the mirror'. Even though all the words included do not have a degrading meaning, the phrase 'do you even go to school' implies stupidity because the question asks if the person 
learned anything in school. Meanwhile, the phrase 'Please look at the mirror' implies that a person is ugly.

Furthermore, the answers revealed a sarcastic manner of delivering mortifying cyberbullying messages to others. For instance, the phrases 'so clever of you', 'she thinks she is so beautiful', 'who do you think you are' and 'I don't need you' carry sarcasm that implicates mortifying messages to others. The phrase 'so clever of you' is a Malaysian way of sarcastically telling a person that he or she is showing off. Next, the phrase 'she thinks she is so beautiful' implies that a person is being delusional about her beauty. The phrase 'who do you think you are' carries the implicit meaning of questioning the worthiness of another person. Lastly, the phrase 'I don't need you' is denying the worthiness of another person.

To conclude, regardless of the straight or sarcastic delivery of demeaning or cyberbullying messages to others, these responses remain a cyberbullying offence. Additionally, people of different cultural backgrounds have different interpretations of the same words and phrases, and thus cause misunderstanding in the delivery process. Therefore, for safety, avoiding intentions to deliver cyberbullying messages to others is ideal.

The data collected likewise revealed unpopular words such as 'derp'. According to the Oxford Dictionary, 'derp' is used as a substitute of speech for people regarded as meaningless or stupid or to comment on a foolish or stupid action. Even though this word is not commonly used to describe others, the meaning still describes someone or someone's action as stupid. Thus, when commenting on social media, avoid using this word and other unpopular or uncommon words to describe others. The globalization era allows for access to information at our fingertips, and true meanings of even unpopular words will be discovered eventually.

\section{Pedagogical Implications}

By understanding and identifying the words and messages presumed as demeaning by the public, related stakeholders can start creating measures to prevent the prevalence of cyberbullying.

First and foremost, teachers in schools at all levels can start with themselves by avoiding the use of the identified words and phrases that demean others in their teaching process, and especially in describing their students, regardless of their appearance, intelligence level or worthiness. Teachers can also be more alert in school grounds. Once they notice that any of their students are involved in using the identified words and phrases to their peers and friends, suitable actions must be taken immediately to deal with the problem and prevent its spread. Nevertheless, those words and phrases remain in the English language that students learn; therefore, teachers need to carefully explain and stress the consequences of misusing such words and phrases.

Next is the role of parents at home. Children and adolescents today have the luxury of digital gadgets and free access to the Internet at all times. Yet, as long as the children and adolescents are underage, then their actions and behaviours need to be watched and controlled by parents. First, parents need to educate their children and cultivate a sense of empathy towards others to prevent cyberbullying acts. Parents need to teach their children to be responsible about their behaviours on the Internet. Moreover, parents need to check their children's social media content to prevent them from using words that carry cyberbullying messages for other children's social media accounts. Next, parents can always collaborate with teachers to be aware of their children's behaviours and learn the words that 
are not suitable to describe children. Children who are growing up always try to imitate what they are exposed to; thus, if teachers and parents do not use demeaning words, the children will not learn or use them.

The last implication is the suggestion to the MCMC. By identifying several of the degrading and demeaning words and phrases presumed as cyberbullying by the public, the MCMC could implement a stronger filter on the Internet to ban the use of such words and phrases among users of social media in Malaysia. Although this is a difficult task and is bound to receive public disapproval for restricting freedom of speech on social media, the people should bear in mind that the goal of this task is to thoroughly solve the rising cyberbullying in Malaysia. If the MCMC carries the suggested implication to ease cyberbullying, a wider public opinion-gathering procedure, such as a nationwide survey, is necessary to identify more demeaning words and phrases of cyberbullying from the different cultures in the nation.

\section{Conclusion}

Cyberbullying is experiencing exponential growth due to the advancement of technologies in people's daily lives. Identifying the cause of cyberbullying and introducing prevention rules is insufficient. Understanding the languages, specifically the words and phrases that the public presumes to carry a demeaning message can help solve the rising cyberbullying.

After identifying the demeaning words and phrases, all stakeholders of society need to take suitable actions against their use. One party that conducts the necessary defence against cyberbullying would be insufficient. All stakeholders, including the government, school, teachers, parents, and the children themselves, need to work together for a better society without the threats of cyberbullying.

\section{Recommendations}

The three most frequently recurring words are "ugly", "stupid" and "useless". All stakeholders must bear in mind these words and other words which carry similar meaning as these words and avoid using them. These words must not be used in the presence of students or underage children who still cannot evaluate the merits of such words. Caution must be taken if these words are used at all. Government agencies such as the MCMC needs to create a better filter on the internet for identifying these degrading words. Furthermore, parents need to constantly monitor the websites that their children access regularly and also prevent their children from using these degrading words. Parents and teacher collaboration is also a good way to keep tabs on the changes in their children's behaviours in school so that action can be taken immediately if there is concerns over the behaviour change.

With the cooperation of all stakeholders such as the government, teachers, school, parents and children, cyberbullying can be controlled through the monitoring of the usage of these cyberbullying-related words. . When cyberbullying decreases, suicide cases will inevitably decrease in tandem, thus saving a lot of lives heartaches. The benefits of identifying, understanding and monitoring the use of cyberbullying-related words by the stakeholders are undoubtedly immense.

\section{Acknowledgment}

The authors would like to thank Universiti Kebangsaan Grant coded GUP-2017-079 for the support of the authorship of this paper. 


\section{References}

Amberg, J. S. \& Vause, D. J. (2010). American English-History, structure and usage. Cambridge University Press.

Andriessen, K. (2018). Understanding and measuring the grief experiences of adolescents with a focus on bereavement by suicide. Sydney. The University of New South Wales.

Bechtel, W. \& Graham, G. (2014). A companion to cognitive science. Blackwell Publisher.

Befrienders. (2019). Befrienders Org Malaysia.

Berne, S., Frisen, A. \& Berne, J. (2019). Cyberbullying in childhood and adolescence: Assessment, negative consequences and prevention strategies. Young People and Learning Processes in School and Everyday Life. 2.

Cacioppo, J. T. \& Hawkley, L. C. (2003). Social isolation and health, with an emphasis on underlying mechanisms. Perspectives in Biology and Medicine.

Diamanduros, T. \& Downs, E. (2019). Cyberbullying: Safety and ethical issues facing K-12 digital citizens. Emerging Trends in Cyber Ethics and Education.

Donegan, R. (2012). Bullying and cyberbullying: History, statistics, law prevention and analysis. The Elon Journal of Undergraduate Research in Communication. 3(1).

Dudley, R. (2018). Suicide epidemic is a concern. The Star Online. https://www.thestar.com.my/opinion/letters/2018/06/15/suicide-epidemic-is-aconcern [2 May 2019].

Ghazali, A. H. A., Omar, S. Z., Ahmad, A., Samah, A. A., Abdullah, H., Ramli, S. A. \& Shaffril, H.A.M. (2016). Potential personality traits that explain cyberbullying among youth in Malaysia. International Journal of Academic Research in Business and Social Sciences.

Halpern, J. (2003). What is clinical empathy. Journal of General Internal Medicine.

Hinduja, S. \& Patchin, J. W. (2018). Connecting adolescent suicide to the severity of bullying and cyberbullying. Journal of School Violence.

Kim, J. H., Walsh, E., Pike, K. \& Thompson, E. A. (2019). Cyberbullying and victimization and youth risk: The buffering effects of School Connectedness. The Journal of School Nursing.

Lai, C. S., Mohaffyza, M., Lee, M. F., Salleh, K. M., Sulaiman, N. \& Rosli, D.I. (2017). Prevalence of cyberbullying among students in Malaysian higher learning institutions. Advanced Science Letters.

Lazuras, L., Pyzalski, J., Barkoukis, V. \& Tsorbatzoudis, H. (2012). Empathy and moral disengagement in adolescent cyberbullying: Implications for educational intervention and pedagogical practice. Studia.

Margeviciute, A. (2017). The definition of bullying in compulsory education: From a general to a legal perspective. Baltic Journal of Law \& Politics.

Oxford. (2019). Learner's dictionaries. oxfordlearnersdictionaries.com.

Pillay, S. (2017). Suicide on the rise among Malaysian youth. New Strait Times. https://www.nst.com.my/news/exclusive/2017/05/243354/suicide-rise-amongmalaysian-youth [2 May 2019].

Plemmons, G., Hall, M., Doupnik, S., Gay, J., Brown, C., Browning, W., Casey, R., Freundlich, K., Johnson, D. P., Lind, C., Rehm, K., Thomas, S. \& Williams, D. (2018). Hospitalization for suicide ideation or attempt: 2008-2015. Pediatrics. 141.

Rashid, M. S. A., Mohamed, S. \& Azman, T. A. T. M. (2017). Predicting the intention to cyberbullying and cyberbullying behaviour among the undergraduate students at the 
International Islamic University Malaysia. International Journal of Education, Psychology and Counseling. 2.

Simon, S. (2017). Cyber victimization: School experience of Malaysian cyberbullied teenagers. International Journal of Humannities and Social Sciences.

Umesh, B., Ali, N. N., Farzana, R., Bindal, P. \& Aminah, N. N. (2018). Student and teachers perspective on cyber-bullying. Journal of Forensic Psychology.

Wedayanti, N. P. \& Giantari, I. (2016). Peran pendidikan kewirausahaan dalam memediasi pengaruh norma subjektif terhadap niat berwirausaha. E-Jurnal Manajemen Universitas Udayana.

Yusuf, S., Hassan, M. S. \& Ibrahim, A. M. M. (2018). Cyberbullying among Malaysian children based on research evidence. Encyclopedia of Information Science and Technology. 